\title{
Neural circuitry and plasticity mechanisms underlying delay eyeblink conditioning
}

\author{
John H. Freeman ${ }^{1}$ and Adam B. Steinmetz \\ Department of Psychology and Neuroscience Program, The University of lowa, lowa City, lowa 52242, USA
}

\begin{abstract}
Pavlovian eyeblink conditioning has been used extensively as a model system for examining the neural mechanisms underlying associative learning. Delay eyeblink conditioning depends on the intermediate cerebellum ipsilateral to the conditioned eye. Evidence favors a two-site plasticity model within the cerebellum with long-term depression of parallel fiber synapses on Purkinje cells and long-term potentiation of mossy fiber synapses on neurons in the anterior interpositus nucleus. Conditioned stimulus and unconditioned stimulus inputs arise from the pontine nuclei and inferior olive, respectively, converging in the cerebellar cortex and deep nuclei. Projections from subcortical sensory nuclei to the pontine nuclei that are necessary for eyeblink conditioning are beginning to be identified, and recent studies indicate that there are dynamic interactions between sensory thalamic nuclei and the cerebellum during eyeblink conditioning. Cerebellar output is projected to the magnocellular red nucleus and then to the motor nuclei that generate the blink response(s). Tremendous progress has been made toward determining the neural mechanisms of delay eyeblink conditioning but there are still significant gaps in our understanding of the necessary neural circuitry and plasticity mechanisms underlying cerebellar learning.
\end{abstract}

Eyeblink conditioning is an associative learning paradigm that was first developed for use in human participants in the 1920s (Cason 1922). It was initially valued as a method for studying learning and higher nervous system function without confounds associated with verbal reports, introspection, or prior experience with similar associations. The procedure involves presentation of a conditioned stimulus (CS), typically a tone or light, which is paired with an unconditioned stimulus (US) that reliably elicits eyelid closure, such as an air puff or brief electrical stimulation near the eye. Humans will often show a short-latency lowamplitude unconditioned (alpha) response to an auditory CS. After repeated CS-US trials, conditioned eyelid closure (conditioned response [CR]) occurs during the CS. Maximum eyelid closure for the CR typically occurs near the onset time of the US. Several shortcomings of the paradigm were later identified, most notably, the presence of alpha responses and voluntary responses among human participants who became explicitly aware of the stimulus contingency. These shortcomings and the need for an animal model for invasive neuroscience research led to the development of the rabbit eyeblink and nictitating membrane paradigms (Gormezano et al. 1962; Schneiderman et al. 1962; Gormezano 1966). Rabbits tolerate restraint well, do not exhibit alpha responses, and precise measures of eyelid closure and nictitating membrane movement are obtained readily (Gormezano 1966). Most of the initial work on the neural mechanisms underlying eyeblink conditioning was conducted using rabbits, but the paradigm has been applied to frogs, turtles, mice, rats, ferrets, sheep, dogs, monkeys, and cats. A concern with using species other than rabbit is that most of them will show alpha responses if the CS and US parameters are not adjusted properly. For example, we have found that alpha responses in rodents can be almost completely eliminated by reducing the frequency ( $2 \mathrm{kHz}$ ) and amplitude (70 dB for mice, $80-85 \mathrm{~dB}$ for rats) of an auditory CS and duration of the US $(\leq 25 \mathrm{msec})$. Although there is a rich behavioral literature from studies of eyeblink

\footnotetext{
${ }^{1}$ Corresponding author.

E-mail john-freeman@uiowa.edu.

Article is online at http://www.learnmem.org/cgi/doi/10.1101//m.2023011.
}

conditioning in humans and experimental animals, this review will focus primarily on the neurobiological findings from studies of delay conditioning.

\section{What is an eyeblink?}

It is important to note at this point that the unconditioned response (UR) and CR in eyeblink conditioning differ from each other and from spontaneous blinks in kinematics and neural control (Gruart et al. 1995, 2000; Trigo et al. 1999; Schade Powers et al. 2010). The temporal properties of the CR are determined by the inter-stimulus interval, with the CR peaking near the onset time of the US, whereas the temporal properties of the UR are determined by parameters of the US (Gormezano et al. 1983). Moreover, different types of blinks (URs) are elicited by different stimuli (Gruart et al. 1995; Trigo et al. 1999); the field generally ignores these distinctions, perhaps to our detriment. "Eyeblink" is also typically used synonymously in the literature for eyelid and nictitating membrane movement because, as discussed below, the premotor neural circuitry underlying the respective CRs is the same. However, the motor nuclei that generate eyelid and nictitating membrane movement are distinct (see Response Output Circuitry section). The focus of this review is on the premotor mechanisms of conditioning and will, therefore, use the term "eyeblink" in reference to eyelid and nictitating membrane movements, as well as the CR and UR.

\section{Essential role of the cerebellum in delay conditioning}

Brogden and Gantt (1942) were among the first to demonstrate a role for the cerebellum in associative learning by conditioning discrete movements when electrical stimulation of the cerebellum was used as the US paired with an auditory CS. Eccles et al. (1967) later hypothesized that the cerebellum plays a role in skill learning, based on the physiology and anatomy of the cerebellar cortex. This hypothesis was formalized in computational models by Marr (1969) and Albus (1971). A key component of the Albus model is that cerebellar Purkinje cells undergo learning-related 
inhibition. The current interpretation of this mechanism is that Purkinje cell inhibition releases the deep nuclei from its tonic inhibition. This long-term depression (LTD) mechanism has been verified with various in vivo and in vitro preparations (Ito and Kano 1982; Linden and Connor 1991, 1995; Linden et al. 1991; Linden 1994). One of the first studies to show a cerebellar correlate of learning was an experiment by Gilbert and Thach (Gilbert and Thach 1977) who found decreases in Purkinje cell simple spike activity consistent with the LTD hypothesis during a task requiring monkeys to modify wrist movements to compensate for changes in load. They also found evidence that increases in complex spike activity correspond to novel changes in load. The Gilbert and Thach study showed remarkable correlates of learning and error correction of a simple movement but did not demonstrate that the task-related Purkinje cells were necessary for learning.

Thompson and colleagues were the first to show that the cerebellum plays an essential role in eyeblink conditioning (McCormick et al. 1981, 1982; Lincoln et al. 1982). In their initial studies, aspiration lesions of the cerebellar hemisphere ipsilateral to the conditioned eye were found to abolish CRs while leaving conditioning of the contralateral eye intact. Lesions that included the ipsilateral deep nuclei were the most effective (see also Yeo et al. 1985a). Remarkably, the lesions had no effect on the UR, indicating that performance of the response is not affected by lesions that abolish the CR. More precise lesions, including fiber-sparing neurotoxic lesions, in the cerebellar nuclei identified the lateral portion of the anterior interpositus nucleus as the neuron population essential for retention (Lavond et al. 1985). Moreover, lesions of the interpositus nucleus permanently block acquisition (Steinmetz et al. 1992a,b) and abolish retention after memory consolidation (Christian and Thompson 2005). Inactivation of the anterior interpositus nucleus by cooling, lidocaine, or muscimol reversibly abolishes CRs (Chapman et al. 1990; Clark et al. 1992; Krupa et al. 1993; Hardiman et al. 1996; Garcia and Mauk 1998; Bao et al. 2002; Aksenov et al. 2004; Freeman et al. 2005a). Several reports have challenged the findings and interpretations of the studies listed above (Welsh and Harvey 1989, 1991; Jimenez-Diaz et al. 2004). However, most of the findings from lesion and inactivation studies indicate that the anterior interpositus nucleus is necessary for acquisition and retention of CRs.

Neurophysiological studies further demonstrate that neurons in the anterior, but not posterior, interpositus nucleus exhibit a burst of firing in animals that have learned, which models the amplitude/time-course of the CR (Fig. 1; McCormick et al. 1982; McCormick and Thompson 1984; Berthier and Moore 1990; Gould and Steinmetz 1996; Freeman and Nicholson 2000; Nicholson and Freeman 2002; Choi and Moore 2003; Halverson et al. 2010). Moreover, the burst of activity among these anterior interpositus neurons is observed only when a CR occurs and precedes the onset of the CR within-trials (Nicholson and Freeman 2002; Choi and Moore 2003; Green and Arenos 2007; Halverson et al. 2010). The firing profiles of anterior interpositus neurons suggest that these neurons are driving motor neurons to produce the CR. Further evidence supporting a causal relationship between anterior interpositus activity and production of the CR comes from studies that used electrical stimulation through the recording electrodes to produce eyelid closure (McCormick and Thompson 1984; Freeman and Nicholson 2000; Halverson et al. 2010). In fact, eyelid closure can be produced by stimulation of the anterior interpositus nucleus before training, suggesting that there is a hardwired connection between the cerebellum and premotor neurons that produce the CR. The lesion and extracellular recording studies provide compelling evidence that activity in the anterior interpositus nucleus drives production of the CR.
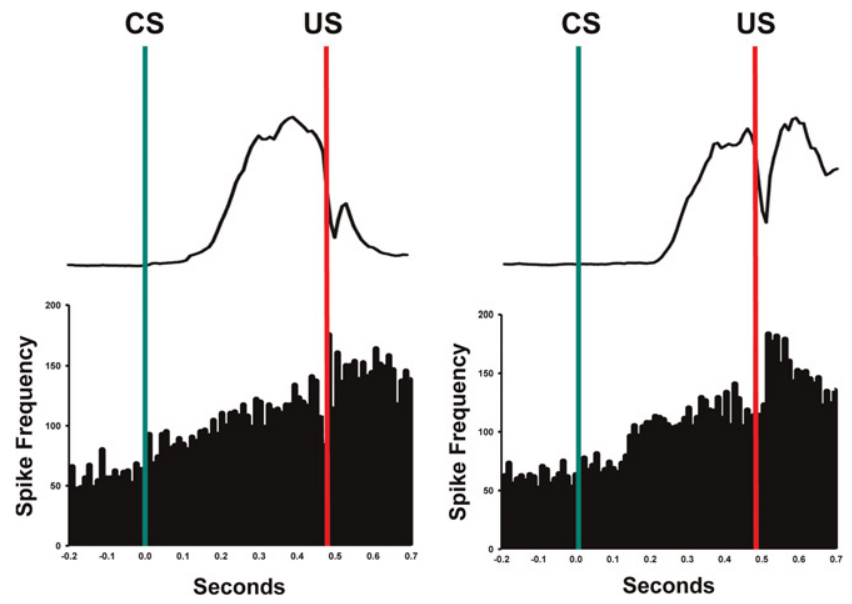

Figure 1. Examples of single unit activity (spikes/sec) recorded from the anterior interpositus nucleus and corresponding average eyelid EMG activity in well-trained rats during CS-US trials. The green line represents CS onset and the red line represents US onset. Bars in the histograms are $10 \mathrm{msec}$. Note the increase in activity after onset of the CS.

Lesions of the cerebellar cortex have most commonly resulted in severely impaired acquisition of eyeblink conditioning (Lavond and Steinmetz 1989; Garcia et al. 1999). Learning in animals with cerebellar cortical damage eventually occurs, in some cases, with extensive training (Lavond and Steinmetz 1989; Chen et al. 1996, 1999; Nolan and Freeman 2006). For example, Lavond and Steinmetz (1989) made large aspiration lesions of the cerebellar cortex that included almost the entire hemisphere in rabbits and found that some of these rabbits acquired eyeblink conditioning with extended training. Particularly convincing demonstrations of the role of the cerebellar cortex in acquisition of eyeblink conditioning come from studies that examined conditioning after global loss of Purkinje cells. Purkinje cells are the presumed site of plasticity within the cerebellar cortex during learning, and their axons form the entire output of the cerebellar cortex. Thus, depleting Purkinje cells removes the influence of cerebellar cortical plasticity and tonic inhibition on the deep nuclei. Mice with mutations resulting in global Purkinje cell loss show slower acquisition and a lower asymptote (Chen et al. 1996, 1999). Furthermore, rats with global loss of Purkinje cells caused by administration of an immunotoxin also show very slow acquisition of eyeblink conditioning (Nolan and Freeman 2006). In contrast, Yeo and colleagues found that rabbits given AMPA receptor blockade failed to acquire eyeblink conditioning (Attwell et al. 2001). A shortcoming of this study, however, was that the rabbits were only trained for 200 trials with AMPA receptor blockade. Thus, it is possible that these rabbits would have eventually learned with further training during AMPA blockade. The findings from studies using various types of lesions have generally shown that the cerebellar cortex plays an important role in acquisition of eyeblink conditioning, but learning can limp along slowly without the cortex.

The findings from studies examining the effects of cortical lesions on retention of eyeblink conditioning are quite variable. Large cerebellar cortical aspirations of the hemisphere result in an initial loss of CRs and subsequent partial or complete relearning with retraining (Lavond et al. 1987; Yeo and Hardiman 1992; Harvey et al. 1993; Woodruff-Pak et al. 1993). A similar pattern of results is found with immunotoxin-induced Purkinje cell loss throughout the cerebellar cortex (Nolan and Freeman 2005). In some studies, the amount of recovery depends on the extent of damage to lobule HVI and neighboring areas of the ansiform 
lobule (Yeo and Hardiman 1992; Harvey et al. 1993). The amount of prelesion training may also be related to the rate and magnitude of post-lesion recovery following lesions of lobule HVI (Harvey et al. 1993). Smaller lesions of the cerebellar cortex localized to the anterior lobe cause a disruption of CR timing without a substantial reduction in CR percentage (Perrett et al. 1993). It is possible, therefore, that the anterior lobe and lobule HVI make different contributions to eyeblink conditioning after learning.

Pharmacological studies of interactions between the cerebellar cortex and deep nuclei have revealed much more about their respective roles in conditioning and memory storage mechanisms than the lesion studies. Controversies over the myriad factors that could lead to different results following lesions led to studies that used pharmacological disconnection of the cerebellar cortex from the deep nuclei (Mauk 1997). This is an experimentally tractable approach because the entire output of the cerebellar cortex goes to the cerebellar and vestibular nuclei, and it is GABAergic. Thus, drugs that block GABAergic synaptic transmission block cortical input to the deep nuclei. Several studies used this pharmacological disconnection approach and found that blocking GABA-A synaptic transmission with the GABA-A chloride channel blocker picrotoxin or the GABA-A receptor antagonist gabazine resulted in short-latency CRs; that is, CR timing was disrupted (Garcia and Mauk 1998; Medina et al. 2001; Ohyama et al. 2003, 2006; Parker et al. 2009; Vogel et al. 2009). Furthermore, CR percentage was only reduced when high doses of picrotoxin were administered. A concern about the use of picrotoxin to block synaptic transmission is that it also causes tonic disinhibition of deep nucleus neurons (Aksenov et al. 2004). A study by Thompson and colleagues used sequential administration of muscimol and picrotoxin in the interpositus nucleus to block GABA-A synaptic input from the cerebellar cortex while adjusting tonic inhibition within the interpositus nucleus (Bao et al. 2002). When this sequential infusion procedure was used in rabbits that had acquired eyeblink conditioning, CRs were initially abolished but recovered as picrotoxin was infused, suggesting that release from tonic inhibition was sufficient to restore CRs. However, the recovered CRs had shorter onset latencies indicating that CR timing was disrupted by blocking synaptic transmission from Purkinje cells. Thus, as in the prior studies, blocking GABA-A synaptic transmission from Purkinje cells to the interpositus nucleus impaired timing of the CR. These findings also indicate that a memory trace that is sufficient for a basic, untimed CR is established within the interpositus nucleus during eyeblink conditioning (Ohyama et al. 2006).

Why do the findings from lesion and pharmacological studies differ regarding retention of CR frequency? Lesions are typically followed by a recovery period $>1 \mathrm{wk}$. Brain areas afferent and efferent to the lesion site may undergo reactive and compensatory changes following the lesion that could affect post-operative performance. Temporary alterations in synaptic function within the deep nuclei produce changes in tonic and phasic activity in downstream circuitry but do not produce the chronic changes in neural circuitry seen with lesions. Lesions of the cerebellar cortex have been shown to increase gliosis within the interpositus nucleus (Yeo et al. 1985b; Harvey et al. 1993). The effects of gliosis on interpositus neuronal function have not been determined, but the loss of Purkinje cell innervation of the deep nuclei could result in myriad other changes in neuronal function. For example, neurons in the interpositus nucleus may make compensatory changes in glutamatergic synaptic efficacy or intrinsic excitability following the loss of tonic inhibition from the cortex to prevent excitotoxicity; these compensatory changes could, in turn, impair performance of the CR by weakening CS input from mossy fibers. Another mechanism is suggested by studies that showed degeneration of the inferior olive following cerebellar cortical lesions (Yeo et al. 1985b;
Lavond et al. 1987). The loss of inferior olive neurons and damage to the cortex itself would be expected to reduce climbing fiber collateral innervation of the deep nuclei, which may impair retention of plasticity within the deep nuclei by eliminating a source of neural reinforcement. The causal factors leading to differences between the effects of cerebellar cortical lesions and pharmacological disconnection have not been determined but may be attributable to reactive chronic vs. acute effects of the manipulations on the physiology of neurons in the interpositus nucleus.

The Gilbert and Thach (1977) study showed examples of Purkinje cells that exhibited decreased simple spike activity during adaptation of wrist movements to novel loads. These decreases in simple spike activity were interpreted as being consistent with the Albus theory of cerebellar learning (Albus 1971). Several studies have found similar decreases in simple spike activity during eyeblink conditioning. A large proportion of Purkinje cells in the anterior lobe and neighboring parts of lobule HVI decreased simple spike activity during the CS in well trained rabbits, particularly later in the CS-US interval where the CR is produced (Green and Steinmetz 2005). These decreases in simple spike activity were also appropriately timed to different inter-stimulus intervals. Later, a somewhat constrained but well-controlled study found that eyeblink conditioning using electrical stimulation of the forearm as CS in decerebrated ferrets produced pauses in Purkinje cell activity within blink zones of the cerebellar cortex (Jirenhed et al. 2007). The pauses in simple spike activity were abolished by extinction training but reacquired with the resumption of CS-US pairings. Interpretation of these findings is somewhat constrained by the absence of a behavioral response, precluding the possibility of relating the development of pauses in simple spike activity to the development of the CR across trials or relating the timing of the pauses to timing of the CR. A critical study for the field would be to record the activity of blink-related Purkinje cells during acquisition and extinction in intact animals to relate pauses in simple spikes to the development and extinction of behavioral CRs.

It is clear that the cerebellar cortex and anterior interpositus nucleus ipsilateral to the conditioned eye play critical roles in acquisition and retention of eyeblink conditioning. Lesions and inactivation of relevant cortical areas or the anterior interpositus nucleus impair acquisition, and neurons within these areas show activity profiles that correlate with the development of the eyeblink CR across CS-US trials and within trials. Moreover, the dynamics of neuronal activity during trials indicate that pauses in Purkinje cell simple spike activity release the anterior interpositus nucleus from inhibition, and the burst of activity from the nucleus drives premotor and motor neurons to generate the CR.

The role of the cerebellum in associative learning has been primarily examined using eyeblink conditioning. However, the cerebellum is essential for other Pavlovian CRs, including conditioned forelimb flexion in cats (Voneida 2000) and conditioned hind limb flexion in rabbits (Mojtahedian et al. 2007). The cerebellum also contributes to learned adjustments to movements (Gilbert and Thach 1977), gaze-reach calibrations (Norris et al. 2011), gain modification of the vestibulo-ocular reflex (Raymond et al. 1996; Boyden et al. 2004), and learned smooth pursuit eye movements (Medina and Lisberger 2008).

\section{Localization of the memory trace within the cerebellum}

The studies reviewed so far show that the cerebellum is necessary for acquisition and retention of eyeblink conditioning. None of these studies, however, demonstrates definitively that the memory underlying the CR is stored exclusively within the cerebellum. 
Reversible inactivation of various parts of the cerebellar circuitry has been used systematically to argue that the memory underlying eyeblink conditioning must be stored within the cerebellum. The logic of this approach is that inactivation of a brain area that stores the memory should result in no CRs during acquisition and, more importantly, should result in no savings after the inactivation has been removed. That is, the rate of acquisition following inactivation should be the same as initial acquisition in an appropriate control group. In contrast, if inactivation prevents CRs during acquisition, but savings is seen after inactivation has been removed, the conclusion is that the region inactivated is involved in expression of learning but does not store memory underlying the CR. Inactivation of the cerebellar nuclei and neighboring cortical areas blocks CRs during acquisition and results in no savings in subsequent training without inactivation (Clark et al. 1992; Krupa et al. 1993; Krupa and Thompson 1997; Freeman et al. 2005a). These findings indicate that structures afferent to the cerebellum cannot be storing the memory, but another possibility is that efferent structures could be storing the memory, and cerebellar inactivation simply blocked the relay of efferent stimulation to the downstream site of memory storage. Inactivation of the output pathway of the cerebellum, the superior cerebellar peduncle, the red nucleus, or motor nuclei necessary for generating the eyeblink response(s) results in abolition of CRs during acquisition but complete savings during subsequent training without inactivation (Clark and Lavond 1993; Krupa et al. 1993, 1996; Krupa and Thompson 1995). Furthermore, inactivation of the red nucleus blocks CRs but does not affect learning-related activity within the cerebellum (Chapman et al. 1990). These findings indicate that the red nucleus and motor nuclei are premotor and motor areas, respectively, that are downstream of the site of memory storage.

Reversible inactivation has also been used to examine consolidation of eyeblink conditioning. Post-training inactivation of the cerebellar cortex blocks retention of eyeblink conditioning in rabbits, providing further evidence that the memory underlying the eyeblink CR is stored within the cerebellum (Attwell et al. 2002; Cooke et al. 2004). Unfortunately, these studies are somewhat limited because post-training inactivation was used for only 200 trials, raising the possibility that the rabbits might have learned with more training. Nevertheless, these findings add to the evidence that the memory underlying eyeblink conditioning is stored within the cerebellum. The findings specifically suggest that there is memory storage within the cortex, as proposed by Albus (1971) and Marr (1969).

A series of experiments subsequently demonstrated evidence for memory storage within the anterior interpositus nucleus (Ohyama et al. 2006). The approach of this study was to pharmacologically disconnect the cerebellar cortex from the interpositus nucleus, resulting in short-latency CRs, and then to examine the mechanisms underlying these poorly timed responses using pharmacological manipulations and electrical stimulation. Plasticity mechanisms afferent and efferent to the anterior interpositus nucleus were ruled out by this analysis. The results indicate that the memory underlying expression of short-latency CRs is most likely stored within the anterior interpositus nucleus.

A general conclusion drawn from the Ohyama et al. (2006) study and others is that plasticity mechanisms occur within the cortex to support an LTD-like mechanism and in the anterior interpositus nucleus to support an LTP-like mechanism. Cellular and molecular mechanisms underlying cerebellar memory have been examined with multiple approaches. Genetic and pharmacological manipulations that impair cerebellar cortical LTD generally impair eyeblink conditioning (Aiba et al. 1994; Shibuki et al. 1996; Ichise et al. 2000; Kishimoto et al. 2002; Lee et al. 2009). For example, genetic manipulations of mGluR1 function impair LTD and eyeblink conditioning in mice (Aiba et al. 1994; Ichise et al. 2000; Kishimoto et al. 2002). More global manipulations of plasticity mechanisms within the cerebellum, including blockade of protein synthesis, NMDA receptors, and kinase activity, all impair eyeblink conditioning (Bracha et al. 1998; Gomi et al. 1999; Chen and Steinmetz 2000a, b). Several studies have also found evidence for structural plasticity within the cerebellum following eyeblink conditioning. For example, the number of excitatory synapses per neuron within the anterior interpositus nucleus was significantly elevated following eyeblink conditioning in well-trained rats (Kleim et al. 2002). Changes in synapse morphology but not number were seen within the anterior interpositus nucleus in rabbits following less extensive training (Weeks et al. 2007). Changes in synapse structure have also been found in the cerebellar cortex following eyeblink conditioning. Rabbits given $3 \mathrm{~d}$ of eyeblink conditioning showed a reduction of excitatory parallel fiber synapses with Purkinje cells (Connor et al. 2009). Thus, the morphological studies of synaptic plasticity have found synaptic changes that might underlie an LTP-like mechanism in the anterior interpositus nucleus and an LTD-like mechanism in the cerebellar cortex. The studies of plasticity mechanisms underlying eyeblink conditioning collectively provide further evidence of memory storage within the cerebellum.

\section{Response output circuitry}

The neurophysiological studies cited above indicate that anterior interpositus nucleus activity drives the CR indirectly through premotor neurons. The magnocellular division of the red nucleus receives projections from the cerebellar nuclei and projects to motor neurons that control the eyeblink response(s) (Desmond et al. 1983; Rosenfield and Moore 1983, 1985; Rosenfield et al. 1985; Clark and Lavond 1993). Stimulation of the red nucleus, with proper parameters, thereby produces an eyeblink response (Chapman et al. 1988; Nowak et al. 1997). Neurons in the red nucleus develop learning-related activity that closely resembles interpositus activity (Desmond and Moore 1991). Moreover, inactivation of the red nucleus abolishes CRs while leaving learningrelated activity in the interpositus nucleus intact (Chapman et al. 1990). This finding and the findings from inactivation studies (see Localization of the Memory Trace within the Cerebellum section) indicate that the red nucleus is necessary for producing the CR but is not a site of memory storage.

The magnocellular red nucleus has excitatory projections to the motor nuclei that generate the various eyeblink responses, which include the nictitating membrane and eyelid movement CR and UR. Movement of the nictitating membrane is a passive response to eyeball retraction generated by motor neurons in the abducens and accessory abducens nucleus (Harvey and Gormezano 1981; Harvey et al. 1984; Marek et al. 1984; Disterhoft et al. 1985; Weiss and Disterhoft 1985). The accessory abducens nucleus receives sensory relay input from the trigeminal nuclei and reticular brainstem (Harvey et al. 1984). The activity of abducens motor neurons has an amplitude/time-course profile that closely mirrors the nictitating membrane response in rabbits for the UR and CR (Cegavske and Thompson 1976; Cegavske et al. 1979).

Eyelid movement is generated by the facial motor nucleus (Pellegrini et al. 1995; Trigo et al. 1999). The neurophysiological studies of Delgado-Garcia and colleagues demonstrated how patterns of facial motor neuron firing result in the dynamic profiles of eyelid closure for different types of responses (Trigo et al. 1999). The sensory relays necessary for activating the blink motor neurons include the trigeminal nuclei and cervical spinal cord (Pellegrini et al. 1995). Both the eyelid movement and nictitating membrane UR are initiated by the afferent sensory fibers arising 
from the cornea, in the case of an air puff stimulus, or from the periorbital area, in the case of a shock stimulus.

\section{Unconditioned stimulus input circuitry}

Trigeminal and spinal areas that receive sensory afferents from the cornea and face project to the inferior olive. Neurons in the dorsal accessory inferior olive (DAO) typically fire one or two action potentials in response to a US (Kim et al. 1998; Nicholson and Freeman 2003a). Inferior olive neurons fire synchronously because of electrotonic coupling (Llinas et al. 1974; Llinas and Yarom 1981a,b; Lang et al. 1996). The axons of inferior olive neurons become climbing fibers within the cerebellum and have collateral synapses with neurons in the deep nuclei and Purkinje cells in the cortex (Sugihara et al. 1999, 2001; Shinoda et al. 2000). Climbing fibers make very powerful synaptic contacts with Purkinje cells, resulting in a multiphase complex spike (Llinas and Sugimori 1980). As mentioned above, early models of cerebellar function posited that complex spikes provide input from a US or an error signal that drives synaptic modifications of Purkinje cells during learning (Marr 1969; Albus 1971).

Lesions of the inferior olive impair acquisition of eyeblink conditioning (Mintz et al. 1994; Welsh and Harvey 1998). Post-training lesions or inactivation produce an extinction-like decrease in CRs or an immediate loss of CRs (McCormick et al. 1985; Yeo et al. 1986; Welsh and Harvey 1998; Zbarska et al. 2007). An extinction-like decrease in limb-flexion CRs was also observed following inferior olive lesions in cats (Voneida et al. 1990). The basis for the different findings of post-training lesions of the inferior olive is somewhat mysterious at this point, but it may have to do with the time-course of the Purkinje cell response to the loss of climbing fiber input, which produces pauses in simple spike activity that, in turn, influence the excitability of neurons in the deep nuclei (Bengtsson et al. 2004). Perhaps the strongest evidence that the inferior olive is part of the US pathway is that electrical stimulation of the DAO can serve as an effective US and supports conditioning when paired with a CS (Mauk et al. 1986; Steinmetz et al. 1989). Conditioning established with DAO stimulation requires CS-US pairing with an interstimulus interval that supports conditioning with peripheral USs. CRs established with DAO stimulation as the US also exhibit extinction during CS-alone trials.

The inferior olive receives an inhibitory feedback projection from the cerebellar nuclei that plays important roles in eyeblink conditioning (Andersson et al. 1988; Sears and Steinmetz 1991; Medina et al. 2002; Nicholson and Freeman 2003a; Bengtsson et al. 2004, 2007; Bengtsson and Hesslow 2006; Svensson et al. 2006). Blocking GABAergic function within the inferior olive acts upon the electrotonic coupling mechanism, alters the synchrony of firing among olive neurons, and increases baseline firing rates (Lang et al. 1996; Medina et al. 2002; Nicholson and Freeman 2003a,b). Inhibitory feedback is thought to regulate plasticity in the cerebellum by altering the rate of climbing fiber activity in the cortex-increases resulting in LTD and decreases resulting in LTP (Medina et al. 2002). Cerebellar inhibitory feedback to the inferior olive is also the basis for the blocking effect in which the addition of a new and redundant CS is not conditioned (Kim et al. 1998).

\section{Conditioned stimulus input circuitry}

The middle cerebellar peduncle consists of mossy fiber axons projecting to the cerebellum from various subcortical sources including the basilar pontine nuclei (Shinoda et al. 1992, 2000; Mihailoff 1993). Pontine nuclei (PN) receive a massive amount of sensory information from cerebral cortical sensory areas and subcortical sensory nuclei (Glickstein et al. 1972, 1980; Mihailoff and Watt 1981; Mihailoff et al. 1985, 1989; Kosinski et al. 1988; Legg et al. 1989; Wells et al. 1989). Much of this sensory information is relayed to the cerebellar deep nuclei and granule cell layer of the cortex (Shinoda et al. 1992, 2000; Mihailoff 1993). Lesions of the middle cerebellar peduncle abolish learning with auditory, visual, or tactile CSs (Solomon et al. 1986; Lewis et al. 1987). The sufficiency of the mossy fiber projection as a CS was demonstrated by a series of studies that used pontine or middle cerebellar peduncle stimulation as a CS paired with a peripheral US (Steinmetz et al. 1986; Rosen et al. 1989; Steinmetz 1990; Tracy et al. 1998; Hesslow et al. 1999; Bao et al. 2000; Freeman and Rabinak 2004; Freeman et al. 2005b). Mossy fiber stimulation is a highly effective CS for eyeblink conditioning. Moreover, the parameters that support conditioning and extinction with peripheral and mossy fiber CSs are very similar. Electrical stimulation can, of course, cause antidromic activation and activation (or inhibition) of unintended targets. This general concern was allayed by experiments that showed abolition of CRs established with mossy fiber stimulation by lesions or inactivation of the anterior interpositus nucleus (Steinmetz et al. 1986; Freeman and Rabinak 2004; Freeman et al. 2005b). Hesslow and colleagues also established eyeblink conditioning with a mossy fiber stimulation CS in combination with a sodium channel blocker within the middle cerebellar peduncle that was distal to the stimulation electrode to prevent antidromic activation of brainstem neurons (Hesslow et al. 1999). Collectively, the lesion and stimulation studies indicate that CS information, regardless of sensory modality, is projected to the cerebellum via mossy fibers.

\section{Auditory CS pathway}

Auditory cortical projections to the pontine nuclei are relatively prominent, but lesions of the cerebral cortex that include the auditory cortex do not prevent acquisition or retention of delay eyeblink conditioning (Oakley and Russell 1972, 1977). The subcortical auditory CS pathway was initially investigated by Steinmetz and colleagues using rabbits (Steinmetz et al. 1987). The lateral nuclei of the basilar pons were identified as the source of mossy fiber auditory input to the cerebellum using posttraining lesions. Rabbits given electrolytic lesions of the lateral pontine nuclei after acquisition of auditory eyeblink conditioning were severely impaired. These rabbits were unimpaired, however, when tested with a visual CS. A projection from the ventral cochlear nucleus to the lateral pons was identified and thought to be a likely source of short-latency auditory input to the pons, which was seen with auditory-evoked field potential recordings. Based on this set of findings, Steinmetz et al. (1987) concluded that the most likely auditory CS pathway was the cochlear nucleus projection to the lateral pontine nuclei but acknowledged that other auditory inputs could play a role.

Subsequent studies found that the inferior colliculus and auditory thalamus also play a role in auditory eyeblink conditioning in rats. Unilateral lesions of the inferior colliculus or medial geniculate and neighboring thalamic nuclei contralateral to the conditioned eye severely impair acquisition of delay eyeblink conditioning with a tone CS (Halverson and Freeman 2006; Freeman et al. 2007). Lesions restricted to the dorsal and ventral divisions of the medial geniculate have no effect, but lesions of the medial auditory thalamic nuclei (MATN), including the medial division of the medial geniculate, posterior intralaminar nucleus, and suprageniculate nucleus, completely block acquisition of auditory eyeblink conditioning. Rats with lesions of the MATN are completely unimpaired when trained with a visual CS, indicating 
that the impairment is modality-specific. Anterograde and retrograde tract tracing experiments revealed a monosynaptic ipsilateral projection from the MATN to the pontine nuclei, and stimulation of this projection as a CS is sufficient to produce rapid acquisition of eyeblink conditioning (Campolattaro et al. 2007). A subsequent study found that the lateral pontine nuclei contralateral to the conditioned eye are critical for relaying auditory CS information from the MATN to the cerebellum (Halverson and Freeman 2010a). The auditory CS pathway thus includes parallel projections from lower auditory brainstem nuclei to the MATN contralateral to the conditioned eye, their ipsilateral projection to the lateral pontine nuclei, and the mossy fiber projection to the cerebellar cortex and anterior interpositus nucleus ipsilateral to the conditioned eye (Fig. 2).

Neuronal recordings from the pontine nuclei during auditory eyeblink conditioning indicate that pontine neurons primarily show short-latency responses to the CS at the beginning of training but subsequently show increases in activity toward the end of the CS-US period (Clark et al. 1997; Bao et al. 2000; Freeman and Muckler 2003; Campolattaro et al. 2011). This learning-related profile is abolished by inactivation of the cerebellum, suggesting that feedback from the cerebellum drives the learning-related pontine activity (Cartford et al. 1997; Clark et al. 1997; Bao et al. 2000). A similar pattern of results has been obtained with neuronal recordings within the MATN contralateral to the conditioned eye (Halverson et al. 2010). MATN neurons also exhibit learning-related activity during conditioning (O'Connor et al. 1997; Halverson et al. 2010), and simultaneous recordings of MATN and anterior interpositus neurons demonstrated that learning-related increases in activity within the MATN followed learning-related increases in cerebellar activity within training trials, suggesting that cerebellar feedback may be driving learning-related activity in the thalamus (Halverson et al. 2010). The findings of these neurophysiological studies suggest that there is a positive feedback loop between the cerebellum and its auditory CS pathway. This positive feedback may facilitate the rate and asymptote of eyeblink conditioning by strengthening CS input to the cerebellum (Fig. 3).

\section{Visual CS pathway}

As with the auditory CS pathway, decortication or lesions of the sensory cortex do not prevent acquisition or retention of visual delay eyeblink conditioning (Hilgard and Marquis 1935, 1936; Oakley and Russell 1975, 1976, 1977).

Subsequent analysis of cortical and subcortical inputs to the pontine nuclei in rabbits suggested a parallel visual CS pathway including the lateral geniculate nucleus (LGN), superior colliculus (SC), visual cortex (VCTX), and pretectal nuclei (Koutalidis et al. 1988). Bilateral lesions of the LGN, SC, VCTX, or pretectal nuclei

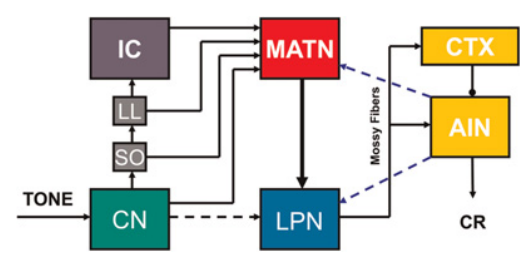

Figure 2. Hypothesized auditory CS pathway for eyeblink conditioning. There are parallel inputs into the medial auditory thalamic nuclei (MATN) from the cochlear nucleus (CN), superior olive (SO), nucleus of the lateral lemniscus (LL), and inferior colliculus (IC). Auditory input is then projected from the MATN to the lateral pontine nuclei (LPN), which project to the cerebellar cortex (CTX) and anterior interpositus nucleus (AIN). Hypothesized feedback projections from the AIN to the LPN and MATN are also shown (blue dashed lines). alone produced a partial impairment; lesions of pairs of these structures produced a more severe impairment, but only combined lesions of all of these areas completely blocked acquisition of eyeblink conditioning with a light CS (Koutalidis et al. 1988). Stimulation of the VCTX, SC, and ventral LGN contralateral to the conditioned eye support eyeblink conditioning in rats, and each of these structures has a direct unilateral projection to the PN that could be important for eyeblink conditioning (Glickstein et al. 1972; Graybiel 1974; Mower et al. 1980; Legg et al. 1989; Wells et al. 1989; Halverson et al. 2009). The pretectal nuclei also have a direct projection to both the medial and lateral PN (Weber and Harting 1980; Wells et al. 1989), but stimulation of the anterior pretectal nucleus is not an effective CS for eyeblink conditioning (Campolattaro et al. 2007). A recent study provided additional support for the parallel model of the visual CS pathway while suggesting that only a subset of the visual inputs to the pons are necessary for eyeblink conditioning (Halverson and Freeman 2010b). Halverson and Freeman (2010b) found that unilateral inactivation of the medial pontine nuclei contralateral to the conditioned eye abolished retention of visual eyeblink conditioning. The area of the medial pons that was inactivated receives monosynaptic input from the ipsilateral ventral LGN and the nucleus of the optic tract (Halverson and Freeman 2010b). The results of the Halverson and Freeman (2010b) study suggest that the visual CS pathway consists of unilateral parallel input from the ventral LGN and nucleus of the optic tract to the medial basilar pons and its mossy fiber projection to the cerebellar cortex and anterior interpositus nucleus (Fig. 4).

\section{Somatosensory CS pathway}

Vibratory stimulation activates spinal afferents that project to the dorsal column nuclei. The dorsal column nuclei then project to the medial pontine nucleus (Kosinski et al. 1986a,b, 1988). The projection of the cuneate nucleus (forelimb and rostral body) is rostral to the projection of the gracile nucleus (hind limb and caudal body). Previous studies in rabbits and ferrets have shown that eyeblink conditioning using stimulation of the body with vibration or weak electrical shocks depends on the middle cerebellar peduncle (Solomon et al. 1986; Lewis et al. 1987; Hesslow et al. 1999). Thus, although there are direct projections from the dorsal column nuclei to the cerebellum through the inferior cerebellar peduncle (Bengtsson and Jorntell 2009), the most likely CS pathway for the vibration CS is the dorsal column nuclear projection to the medial pontine nucleus.

\section{Summary of conditioned stimulus input circuitry}

Conditioned stimulus input pathways that are necessary for delay eyeblink conditioning have not been studied in great detail, but the emerging data indicate that inputs from various subcortical sources are sent to the basilar pons and then through the middle cerebellar peduncle to the cerebellar cortex and deep nuclei. The findings thus far suggest that there is no common circuit structure in CS pathways: The auditory pathway to the pons is primarily serial whereas the visual pathway is parallel. Another circuit difference is that the auditory and visual pathways include thalamic inputs to the pons, whereas the somatosensory pathway arises from medullary nuclei. There may also be differences between CS pathways in the amount of cerebellar feedback and learningrelated plasticity.

\section{Computational models of eyeblink conditioning}

Substantial progress has been made toward identifying the sites of memory storage and synaptic plasticity as well as the input and 

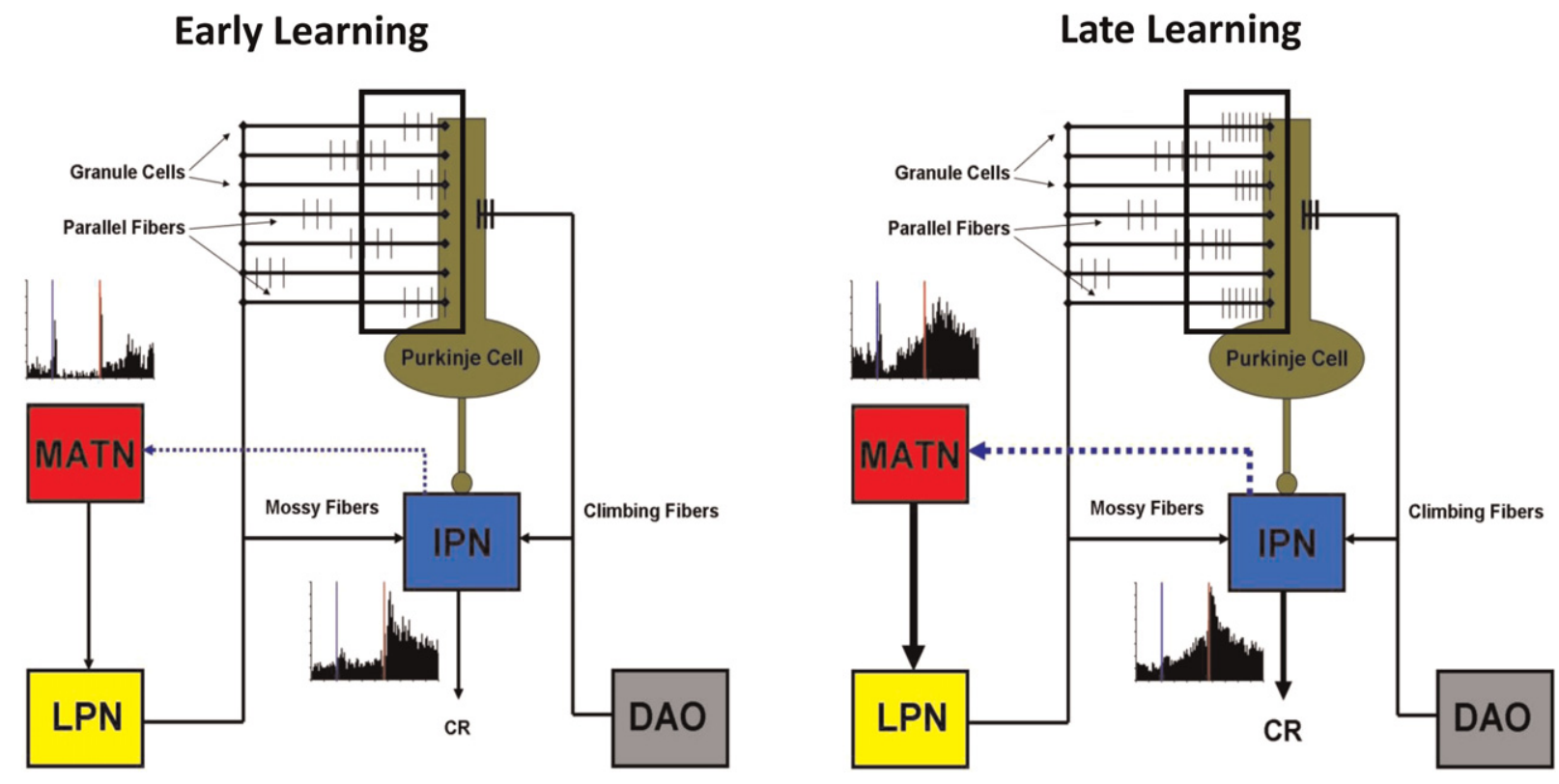

Figure 3. Hypothesized role of medial auditory thalamic plasticity in cerebellar learning. Paired stimulus inputs from the lateral pontine nuclei (LPN) and dorsal accessory inferior olive (DAO) converge on Purkinje cells in the cerebellar cortex during the early stages of eyeblink conditioning (left). Learning is initiated by CS-activated parallel fibers that arrive at Purkinje cells nearly simultaneously with climbing fiber input (window). No learning-related plasticity is evident in the interpositus nucleus (IPN) or medial auditory thalamic nuclei (MATN) during the initial training trials. Paired stimulus inputs from the LPN and DAO continue to converge on Purkinje cells after learning starts to emerge (right). Learning is potentiated by an increase (relative to initial training) in parallel fiber activity that occurs nearly simultaneously with climbing fiber input (window) and mossy fiber activity in the IPN. Clear learning-related plasticity is evident in IPN and MATN during this later stage of learning. An increase in learning-related excitatory cerebellar feedback to the MATN (blue dotted line) may, in turn, increase the MATN output to the LPN and corresponding mossy fiber projection into the cerebellum to further facilitate learning.

output neural circuitry that is necessary and sufficient for delay eyeblink conditioning (Fig. 5). Complex dynamic interactions between elements of the neural circuitry cannot be characterized, however, in static models like the one presented in Figure 5. Computational models have been helpful for characterizing the dynamic nature of cerebellar learning and for generating testable hypotheses for empirical investigation (Moore et al. 1986, 1989; Desmond and Moore 1988; Berthier et al. 1991; Bartha and Thompson 1992; Fiala et al. 1996; Mauk and Donegan 1997; Kenyon et al. 1998a,b; Medina and Mauk 1999, 2000; Medina et al. 2000, 2001; Ohyama et al. 2003; Mauk and Buonomano 2004; Lepora et al. 2010). A particularly promising computational approach has been the computer simulation of the cerebellum by Mauk and colleagues. This simulation includes all of the neuron types within the cerebellum, in correct proportions, with corresponding synaptic relationships. The simulation includes tonic interactions among neurons between training trials as well as phasic changes in activity during presentations of stimuli. The plasticity mechanisms include bidirectional changes in parallel fiber synapses with Purkinje cells and mossy fiber synapses with anterior interpositus neurons. The simulation accurately models many of the findings described above but has also generated several novel hypotheses that have been investigated empirically. For example, the simulation includes tonic and phasic inhibitory feedback from the cerebellum to the inferior olive. A prediction of the model is that the level of activation in the climbing fibers plays a critical role in determining whether parallel fiber synapses with Purkinje cells undergo LTP, LTD, or maintain their current state. Accordingly, extinction is established by decreased climbing fiber activity below the "equilibrium" level which produces LTP, a unique prediction of the simulation that was verified by blocking inhibitory feedback to the inferior olive during extinction training (Medina et al. 2002). This example illustrates how a real-time model that includes the known dynamic interactions between elements of the circuit can accurately simulate learning mechanisms and generate hypotheses. Further development of computer simulations that include interactions with CS input circuitry and forebrain modulatory influences could facilitate a more complete understanding of the mechanisms underlying delay conditioning.

\section{Modulation of delay conditioning}

Several neural systems influence delay conditioning but are not essential for acquisition or retention. A full discussion of this issue is beyond the scope of this review, but it is important to note that hippocampal theta, amygdala, sensory cortex, and norepinephrine inputs to the learning circuitry described above modulate acquisition of eyeblink conditioning (Berry and Thompson 1979; Neufeld and Mintz 2001; Allen et al. 2002; Case et al. 2002; Cartford et al. 2004; Lee and Kim 2004; Blankenship et al.

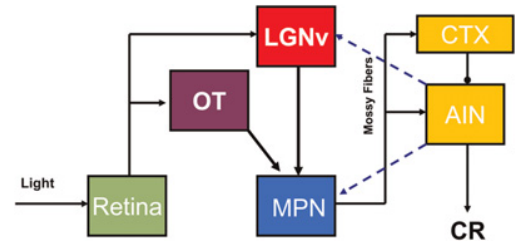

Figure 4. Hypothesized visual CS pathway necessary for delay eyeblink conditioning. Inputs from the retina to the ventral lateral geniculate (LGNv) and nucleus of the optic tract (OT) are relayed in parallel to the cerebellar cortex (CTX) and anterior interpositus nucleus (AIN) via the medial pontine nuclei (MPN). Hypothesized feedback projections from the AIN to the MPN and LGNv are also shown (blue dashed lines). 


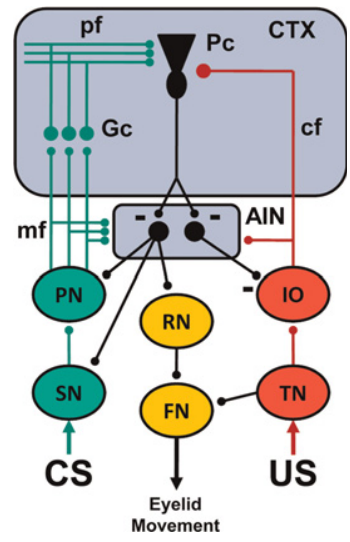

Figure 5. A simplified schematic diagram of the neural circuitry underlying eyeblink conditioning. The cerebellar anterior interpositus nucleus (AIN) and Purkinje cells (PC) in the cerebellar cortex (CTX) receive convergent input from the conditioned stimulus (CS, green) and unconditioned stimulus (US, red) neural pathways. The pathways for different CSs include subcortical sensory nuclei (SN), basilar pontine nuclei (PN), mossy fiber $(\mathrm{mf})$ projection to the AIN and cortical granule cells $(\mathrm{Gc})$, and the parallel fiber (pf) projection to Purkinje cells. The US pathway includes the trigeminal nucleus (TN), dorsal accessory division of the inferior olive (IO), and the climbing fiber (cf) projection to the AIN and Pc. The output pathway for performance of the conditioned response (orange) includes the AIN projection to the red nucleus (RN) and its projection to facial motor nucleus (FN) which causes eyelid closure. The unconditioned response is elicited by activation of the $\mathrm{TN}$, which then activates the FN. Feedback projections from the AIN to the PN, SN, and IO regulate CS and US input to facilitate acquisition and maintain plasticity within the cerebellum. Inhibitory synapses are depicted by a minus sign. All other synapses are excitatory.

2005; Taub and Mintz 2010). A truly comprehensive model of eyeblink conditioning would incorporate modulatory mechanisms in addition to the essential circuitry.

\section{Future directions in eyeblink conditioning}

Although the neural mechanisms underlying delay eyeblink conditioning have been delineated more completely than for any other type of mammalian learning, there are a number of critical issues that require further investigation. At the circuit level, the CS pathways have not been fully determined for any sensory modality nor has the nature of interactions between the few known CS inputs and cerebellar output (Fig. 3). Another important circuit-level issue is characterization of the neural mechanisms underlying forebrain modulation of delay conditioning by the amygdala, hippocampus, and cerebral cortex (Berry and Thompson 1979; Neufeld and Mintz 2001; Allen et al. 2002; Case et al. 2002; Cartford et al. 2004; Lee and Kim 2004; Blankenship et al. 2005; Taub and Mintz 2010). There is evidence that these systems facilitate delay conditioning, but exactly how this facilitation is achieved is currently mysterious.

The cellular and molecular mechanisms underlying cerebellar learning also require further examination. Plasticity mechanisms have been hypothesized and synaptic changes in the cerebellum identified, but the cellular and molecular mechanisms underlying learning-related changes in synapses are unknown. The induction mechanisms for synaptic plasticity in the cerebellum have been modeled in reduced preparations but have not been verified in vivo during conditioning. For example, the cerebellar simulation by Mauk and colleagues predicts that induction of LTD in the cortex is permissive for, and therefore precedes, induction of LTP in the anterior interpositus nucleus (Mauk and
Donegan 1997; Pugh and Raman 2008, 2009), but simultaneous recordings showing that pauses in Purkinje cell simple spikes lead development of increased interpositus activity during initial acquisition have not been conducted. Moreover, the mechanistic relationships between changes in synaptic number or morphology and changes in pathway efficacy have not been determined. Lastly, the role of cerebellar cortical interneurons in eyeblink conditioning has not been examined in detail but is more feasible now that the in vivo firing profiles of identified interneurons have been characterized (Ruigrok et al. 2011). The broad unresolved issues described in this section indicate that the study of delay eyeblink conditioning will continue to be an exciting and active area of investigation for the foreseeable future.

\section{References}

Aiba A, Kano M, Chen C, Stanton ME, Fox GD, Herrup K, Zwingman TA Tonegawa S. 1994. Deficient cerebellar long-term depression and impaired motor learning in mGluR1 mutant mice. Cell 79: 377-388.

Aksenov D, Serdyukova N, Irwin K, Bracha V. 2004. GABA neurotransmission in the cerebellar interposed nuclei: Involvement in classically conditioned eyeblinks and neuronal activity. J Neurophysiol 91: 719-727.

Albus JS. 1971. A theory of cerebellar function. Math Biosci 10: 25-61.

Allen MT, Padilla Y, Gluck MA. 2002. Ibotenic acid lesions of the medial septum retard delay eyeblink conditioning in rabbits (Oryctolagus cuniculus). Behav Neurosci 116: 733-738.

Andersson G, Garwicz M, Hesslow G. 1988. Evidence for a GABA-mediated cerebellar inhibition of the inferior olive in the cat. Exp Brain Res 72: $450-456$.

Attwell PJ, Rahman S, Yeo CH. 2001. Acquisition of eyeblink conditioning is critically dependent on normal function in cerebellar cortical lobule HVI. J Neurosci 21: 5715-5722.

Attwell PJ, Cooke SF, Yeo CH. 2002. Cerebellar function in consolidation of a motor memory. Neuron 34: 1011-1020.

Bao S, Chen L, Thompson RF. 2000. Learning- and cerebellum-dependent neuronal activity in the lateral pontine nucleus. Behav Neurosci 114: 254-261.

Bao S, Chen L, Kim JJ, Thompson RF. 2002. Cerebellar cortical inhibition and classical eyeblink conditioning. Proc Natl Acad Sci 99: 1592-1597.

Bartha GT, Thompson RF. 1992. Control of rabbit nictitating membrane movements. II. Analysis of the relation of motoneuron activity to behavior. Biol Cybern 68: 145-154.

Bengtsson F, Hesslow G. 2006. Cerebellar control of the inferior olive. Cerebellum 5: 7-14.

Bengtsson F, Jorntell H. 2009. Sensory transmission in cerebellar granule cells relies on similarly coded mossy fiber inputs. Proc Natl Acad Sci 106: 2389-2394.

Bengtsson F, Svensson P, Hesslow G. 2004. Feedback control of Purkinje cell activity by the cerebello-olivary pathway. Eur J Neurosci 20: 2999-3005.

Bengtsson F, Jirenhed DA, Svensson P, Hesslow G. 2007. Extinction of conditioned blink responses by cerebello-olivary pathway stimulation. Neuroreport 18: 1479-1482.

Berry SD, Thompson RF. 1979. Medial septal lesions retard classical conditioning of the nictitating membrane response in rabbits. Science 205: $209-211$.

Berthier NE, Moore JW. 1990. Activity of deep cerebellar nuclear cells during classical conditioning of nictitating membrane extension in rabbits. Exp Brain Res 83: 44-54.

Berthier NE, Barto AG, Moore JW. 1991. Linear systems analysis of the relationship between firing of deep cerebellar neurons and the classically conditioned nictitating membrane response in rabbits. Biol Cybern 65: 99-105.

Blankenship MR, Huckfeldt R, Steinmetz JJ, Steinmetz JE. 2005. The effects of amygdala lesions on hippocampal activity and classical eyeblink conditioning in rats. Brain Res 1035: $120-130$.

Boyden ES, Katoh A, Raymond JL. 2004. Cerebellum-dependent learning: The role of multiple plasticity mechanisms. Annu Rev Neurosci 27: 581-609.

Bracha V, Irwin KB, Webster ML, Wunderlich DA, Stachowiak MK, Bloedel JR. 1998. Microinjections of anisomycin into the intermediate cerebellum during learning affect the acquisition of classically conditioned responses in the rabbit. Brain Res 788: 169-178.

Brogden WJ, Gantt WH. 1942. Intraneural conditioning: Cerebellar conditioned reflexes. Arch Neurol Psychiatry 48: 437-455.

Campolattaro MM, Halverson HE, Freeman JH. 2007. Medial auditory thalamic stimulation as a conditioned stimulus for eyeblink conditioning in rats. Learn Mem 14: 152-159. 
Campolattaro MM, Kashef A, Lee I, Freeman JH. 2011. Neuronal correlates of cross-modal transfer in the cerebellum and pontine nuclei. J Neurosci 31: 4051-4062.

Cartford MC, Gohl EB, Singson M, Lavond DG. 1997. The effects of reversible inactivation of the red nucleus on learning-related and auditory-evoked unit activity in the pontine nuclei of classically conditioned rabbits. Learn Mem 3: 519-531.

Cartford MC, Samec A, Fister M, Bickford PC. 2004. Cerebellar norepinephrine modulates learning of delay classical eyeblink conditioning: Evidence for post-synaptic signaling via PKA. Learn Mem 11: $732-737$.

Case GR, Lavond DG, Thompson RF. 2002. Cortical spreading depression and involvement of the motor cortex, auditory cortex, and cerebellum in eyeblink classical conditioning of the rabbit. Neurobiol Learn Mem 78: 234-245.

Cason H. 1922. The conditioned eyelid reaction. J Exp Psychol 5: 153-196.

Cegavske CF, Thompson RF. 1976. Mechanisms of efferent neuronal control of the reflex nictitating membrane response in rabbit (Oryctolagus cuniculus). J Comp Physiol Psychol 90: 411-423.

Cegavske CF, Patterson MM, Thompson RF. 1979. Neuronal unit activity in the abducens nucleus during classical conditioning of the nictitating membrane response in the rabbit (Oryctolagus cuniculus). J Comp Physiol Psychol 93: 595-609.

Chapman PF, Steinmetz JE, Thompson RF. 1988. Classical conditioning does not occur when direct stimulation of the red nucleus or cerebellar nuclei is the unconditioned stimulus. Brain Res 442: 97-104.

Chapman PF, Steinmetz JE, Sears LL, Thompson RF. 1990. Effects of lidocaine injection in the interpositus nucleus and red nucleus on conditioned behavioral and neuronal responses. Brain Res 537: 149-156.

Chen G, Steinmetz JE. 2000a. Intra-cerebellar infusion of NMDA receptor antagonist AP5 disrupts classical eyeblink conditioning in rabbits. Brain Res 887: $144-156$.

Chen G, Steinmetz JE. 2000b. Microinfusion of protein kinase inhibitor H7 into the cerebellum impairs the acquisition but not the retention of classical eyeblink conditioning in rabbits. Brain Res 856: 193-201.

Chen L, Bao S, Lockard JM, Kim JK, Thompson RF. 1996. Impaired classical eyeblink conditioning in cerebellar-lesioned and Purkinje cell-degeneration (pcd) mutant mice. J Neurosci 16: 2829-2838.

Chen L, Bao S, Thompson RF. 1999. Bilateral lesions of the interpositus nucleus completely prevent eyeblink conditioning in Purkinje cell-degeneration mutant mice. Behav Neurosci 113: 204-210.

Choi JS, Moore JW. 2003. Cerebellar neuronal activity expresses the complex topography of conditioned eyeblink responses. Behav Neurosci 117: $1211-1219$.

Christian KM, Thompson RF. 2005. Long-term storage of an associative memory trace in the cerebellum. Behav Neurosci 119: 526-537.

Clark RE, Lavond DG. 1993. Reversible lesions of the red nucleus during acquisition and retention of a classically conditioned behavior in rabbits. Behav Neurosci 107: 264-270.

Clark RE, Zhang AA, Lavond DG. 1992. Reversible lesions of the cerebellar interpositus nucleus during acquisition and retention of a classically conditioned behavior. Behav Neurosci 106: 879-888.

Clark RE, Gohl EB, Lavond DG. 1997. The learning-related activity that develops in the pontine nuclei during classical eyeblink conditioning is dependent on the interpositus nucleus. Learn Mem 3: 532-544.

Connor S, Bloomfield J, LeBoutillier JC, Thompson RF, Petit TL, Weeks AC. 2009. Eyeblink conditioning leads to fewer synapses in the rabbit cerebellar cortex. Behav Neurosci 123: 856-862.

Cooke SF, Attwell PJ, Yeo CH. 2004. Temporal properties of cerebellardependent memory consolidation. J Neurosci 24: 2934-2941.

Desmond JE, Moore JW. 1988. Adaptive timing in neural networks: The conditioned response. Biol Cybern 58: 405-415.

Desmond JE, Moore JW. 1991. Single-unit activity in red nucleus during the classically conditioned rabbit nictitating membrane response. Neurosci Res 10: $260-279$.

Desmond JE, Rosenfield ME, Moore JW. 1983. An HRP study of the brainstem afferents to the accessory abducens region and dorsolateral pons in rabbit: Implications for the conditioned nictitating membrane response. Brain Res Bull 10: 747-763.

Disterhoft JF, Quinn KJ, Weiss C, Shipley MT. 1985. Accessory abducens nucleus and conditioned eye retraction/nictitating membrane extension in rabbit. J Neurosci 5: 941-950.

Eccles JC, Ito M, Szentágothai J. 1967. The cerebellum as a neuronal machine. Springer-Verlag, Berlin.

Fiala JC, Grossberg S, Bullock D. 1996. Metabotropic glutamate receptor activation in cerebellar Purkinje cells as substrate for adaptive timing of the classically conditioned eyeblink response. J Neurosci 16: 3760-3774.

Freeman JH Jr, Muckler AS. 2003. Developmental changes in eyeblink conditioning and neuronal activity in the pontine nuclei. Learn Mem 10: $337-345$.
Freeman JH Jr, Nicholson DA. 2000. Developmental changes in eyeblink conditioning and neuronal activity in the cerebellar interpositus nucleus. J Neurosci 20: 813-819.

Freeman JH Jr, Rabinak CA. 2004. Eyeblink conditioning in rats using pontine stimulation as a conditioned stimulus. Integr Physiol Behav Sci 39: $180-191$.

Freeman JH Jr, Halverson HE, Poremba A. 2005a. Differential effects of cerebellar inactivation on eyeblink conditioned excitation and inhibition. J Neurosci 25: 889-895.

Freeman JH Jr, Rabinak CA, Campolattaro MM. 2005b. Pontine stimulation overcomes developmental limitations in the neural mechanisms of eyeblink conditioning. Learn Mem 12: 255-259.

Freeman JH, Halverson HE, Hubbard EM. 2007. Inferior colliculus lesions impair eyeblink conditioning in rats. Learn Mem 14: 842-846.

Garcia KS, Mauk MD. 1998. Pharmacological analysis of cerebellar contributions to the timing and expression of conditioned eyelid responses. Neuropharmacology 37: 471-480.

Garcia KS, Steele PM, Mauk MD. 1999. Cerebellar cortex lesions prevent acquisition of conditioned eyelid responses. J Neurosci 19: 10940-10947.

Gilbert PF, Thach WT. 1977. Purkinje cell activity during motor learning. Brain Res 128: 309-328.

Glickstein M, Stein J, King RA. 1972. Visual input to the pontine nuclei. Science 178: 1110-1111.

Glickstein M, Cohen JL, Dixon B, Gibson A, Hollins M, Labossiere E, Robinson F. 1980. Corticopontine visual projections in macaque monkeys. J Comp Neurol 190: 209-229.

Gomi H, Sun W, Finch CE, Itohara S, Yoshimi K, Thompson RF. 1999. Learning induces a CDC2-related protein kinase, KKIAMRE. J Neurosci 19: $9530-9537$.

Gormezano I. 1966. Classical conditioning. In Experimental methods and instrumentation in psychology, (ed. JB Sidowski), Vol. 1, pp. 385-420. McGraw-Hill, New York.

Gormezano I, Schneiderman N, Deaux E, Fuentes I. 1962. Nictitating membrane: Classical conditioning and extinction in the albino rabbit. Science 138: 33-34.

Gormezano I, Kehoe EJ, Marshall BS. 1983. Twenty years of classical conditioning research with the rabbit. Prog Psychobiol Physiol Psychol 10: $197-275$

Gould TJ, Steinmetz JE. 1996. Changes in rabbit cerebellar cortical and interpositus nucleus activity during acquisition, extinction, and backward classical eyelid conditioning. Neurobiol Learn Mem 65: $17-34$.

Graybiel AM. 1974. Visuo-cerebellar and cerebello-visual connections involving the ventral lateral geniculate nucleus. Exp Brain Res 20: 303-306.

Green JT, Arenos JD. 2007. Hippocampal and cerebellar single-unit activity during delay and trace eyeblink conditioning in the rat. Neurobiol Learn Mem 87: 269-284.

Green JT, Steinmetz JE. 2005. Purkinje cell activity in the cerebellar anterior lobe after rabbit eyeblink conditioning. Learn Mem 12: 260-269.

Gruart A, Blazquez P, Delgado-Garcia JM. 1995. Kinematics of spontaneous, reflex, and conditioned eyelid movements in the alert cat. J Neurophysiol 74: 226-248.

Gruart A, Schreurs BG, del Toro ED, Delgado-Garcia JM. 2000. Kinetic and frequency-domain properties of reflex and conditioned eyelid responses in the rabbit. J Neurophysiol 83: 836-852.

Halverson HE, Freeman JH. 2006. Medial auditory thalamic nuclei are necessary for eyeblink conditioning. Behav Neurosci 120: 880-887.

Halverson HE, Freeman JH. 2010a. Medial auditory thalamic input to the lateral pontine nuclei is necessary for auditory eyeblink conditioning. Neurobiol Learn Mem 93: 92-98.

Halverson HE, Freeman JH. 2010b. Ventral lateral geniculate input to the medial pons is necessary for visual eyeblink conditioning in rats. Learn Mem 17: 80-85.

Halverson HE, Hubbard EM, Freeman JH. 2009. Stimulation of the lateral geniculate, superior colliculus, or visual cortex is sufficient for eyeblink conditioning in rats. Learn Mem 16: 300-307.

Halverson HE, Lee I, Freeman JH. 2010. Associative plasticity in the medial auditory thalamus and cerebellar interpositus nucleus during eyeblink conditioning. J Neurosci 30: 8787-8796.

Hardiman MJ, Ramnani N, Yeo CH. 1996. Reversible inactivations of the cerebellum with muscimol prevent the acquisition and extinction of conditioned nictitating membrane responses in the rabbit. Exp Brain Res 110: 235-247.

Harvey JA, Gormezano I. 1981. Effects of haloperidol and pimozide on classical conditioning of the rabbit nictitating membrane response. $J$ Pharmacol Exp Ther 218: 712-719.

Harvey JA, Land T, McMaster SE. 1984. Anatomical study of the rabbit's corneal-VIth nerve reflex: Connections between cornea, trigeminal sensory complex, and the abducens and accessory abducens nuclei. Brain Res 301: 307-321. 
Harvey JA, Welsh JP, Yeo CH, Romano AG. 1993. Recoverable and nonrecoverable deficits in conditioned responses after cerebellar cortical lesions. J Neurosci 13: 1624-1635.

Hesslow G, Svensson P, Ivarsson M. 1999. Learned movements elicited by direct stimulation of cerebellar mossy fiber afferents. Neuron 24: $179-185$.

Hilgard ER, Marquis DG. 1935. Acquisition, extinction, and retention of conditioned lid responses to light in dogs. J Comp Psychol 19: 29-58.

Hilgard ER, Marquis DG. 1936. Conditioned eyelid responses in monkeys with a comparison of dog, monkey, and man. Psychol Monogr 47: 186-198.

Ichise T, Kano M, Hashimoto K, Yanagihara D, Nakao K, Shigemoto R, Katsuki M, Aiba A. 2000. mGluR1 in cerebellar Purkinje cells essential for long-term depression, synapse elimination, and motor coordination. Science 288: 1832-1835.

Ito M, Kano M. 1982. Long-lasting depression of parallel fiber-Purkinje cell transmission induced by conjunctive stimulation of parallel fibers and climbing fibers in the cerebellar cortex. Neurosci Lett 33: 253-258.

Jimenez-Diaz L, Navarro-Lopez JdeD, Gruart A, Delgado-Garcia JM. 2004. Role of cerebellar interpositus nucleus in the genesis and control of reflex and conditioned eyelid responses. J Neurosci 24: 9138-9145.

Jirenhed DA, Bengtsson F, Hesslow G. 2007. Acquisition, extinction, and reacquisition of a cerebellar cortical memory trace. J Neurosci 27: 2493-2502.

Kenyon GT, Medina JF, Mauk MD. 1998a. A mathematical model of the cerebellar-olivary system I: Self-regulating equilibrium of climbing fiber activity. J Comput Neurosci 5: 17-33.

Kenyon GT, Medina JF, Mauk MD. 1998b. A mathematical model of the cerebellar-olivary system II: Motor adaptation through systematic disruption of climbing fiber equilibrium. J Comput Neurosci 5: 71-90.

Kim JJ, Krupa DJ, Thompson RF. 1998. Inhibitory cerebello-olivary projections and blocking effect in classical conditioning. Science 279: $570-573$.

Kishimoto Y, Fujimichi R, Araishi K, Kawahara S, Kano M, Aiba A, Kirino Y 2002. mGluR1 in cerebellar Purkinje cells is required for normal association of temporally contiguous stimuli in classical conditioning. Eur J Neurosci 16: 2416-2424.

Kleim JA, Freeman JH Jr, Bruneau R, Nolan BC, Cooper NR, Zook A, Walters D. 2002. Synapse formation is associated with memory storage in the cerebellum. Proc Natl Acad Sci 99: 13228-13231.

Kosinski RJ, Azizi SA, Border BG, Mihailoff GA. 1986a. Origin and ultrastructural identification of dorsal column nuclear synaptic terminals in the basilar pontine gray of rats. J Comp Neurol 253: 92-104.

Kosinski RJ, Neafsey EJ, Castro AJ. 1986b. A comparative topographical analysis of dorsal column nuclear and cerebral cortical projections to the basilar pontine gray in rats. J Comp Neurol 244: 163-173.

Kosinski RJ, Lee HS, Mihailoff GA. 1988. A double retrograde fluorescent tracing analysis of dorsal column nuclear projections to the basilar pontine nuclei, thalamus, and superior colliculus in the rat. Neurosci Lett 85: 40-46.

Koutalidis O, Foster A, Weisz DJ. 1988. Parallel pathways can conduct visual CS information during classical conditioning of the NM response. $J$ Neurosci 8: 417-427.

Krupa DJ, Thompson RF. 1995. Inactivation of the superior cerebellar peduncle blocks expression but not acquisition of the rabbit's classically conditioned eyeblink response. Proc Natl Acad Sci 92: 5097-5101.

Krupa DJ, Thompson RF. 1997. Reversible inactivation of the cerebellar interpositus nucleus completely prevents acquisition of the classically conditioned eyeblink response. Learn Mem 3: 545-556.

Krupa DJ, Thompson JK, Thompson RF. 1993. Localization of a memory trace in the mammalian brain. Science 260: 989-991.

Krupa DJ, Weng J, Thompson RF. 1996. Inactivation of brainstem motor nuclei blocks expression but not acquisition of the rabbit's classically conditioned eyeblink response. Behav Neurosci 110: 219-227.

Lang EJ, Sugihara I, Llinas R. 1996. GABAergic modulation of complex spike activity by the cerebellar nucleoolivary pathway in rat. $J$ Neurophysiol 76: 255-275.

Lavond DG, Steinmetz JE. 1989. Acquisition of classical conditioning without cerebellar cortex. Behav Brain Res 33: 113-164.

Lavond DG, Hembree TL, Thompson RF. 1985. Effect of kainic acid lesions of the cerebellar interpositus nucleus on eyelid conditioning in the rabbit. Brain Res 326: $179-182$.

Lavond DG, Steinmetz JE, Yokaitis MH, Thompson RF. 1987. Reacquisition of classical conditioning after removal of cerebellar cortex. Exp Brain Res 67: $569-593$

Lee T, Kim JJ. 2004. Differential effects of cerebellar, amygdalar, and hippocampal lesions on classical eyeblink conditioning in rats. $J$ Neurosci 24: 3242-3250.

Lee KH, Chatila TA, Ram RA, Thompson RF. 2009. Impaired memory of eyeblink conditioning in CaMKIV KO mice. Behav Neurosci 123: $438-442$
Legg CR, Mercier B, Glickstein M. 1989. Corticopontine projection in the rat: The distribution of labeled cortical cells after large injections of horseradish peroxidase in the pontine nuclei. J Comp Neurol 286: 427-441.

Lepora NF, Porrill J, Yeo CH, Dean P. 2010. Sensory prediction or motor control? Application of Marr-Albus type models of cerebellar function to classical conditioning. Front Comput Neurosci 4: p140. doi:10.3389/ fncom.2010.00140.

Lewis JL, Lo Turco JJ, Solomon PR. 1987. Lesions of the middle cerebellar peduncle disrupt acquisition and retention of the rabbit's classically conditioned nictitating membrane response. Behav Neurosci 101: $151-157$

Lincoln JS, McCormick DA, Thompson RF. 1982. Ipsilateral cerebellar lesions prevent learning of the classically conditioned nictitating membrane/eyelid response. Brain Res 242: 190-193.

Linden DJ. 1994. Long-term synaptic depression in the mammalian brain. Neuron 12: 457-472.

Linden DJ, Connor JA. 1991. Participation of postsynaptic PKC in cerebellar long-term depression in culture. Science 254: 1656-1659.

Linden DJ, Connor JA. 1995. Long-term synaptic depression. Annu Rev Neurosci 18: 319-357.

Linden DJ, Dickinson MH, Smeyne M, Connor JA. 1991. A long-term depression of AMPA currents in cultured cerebellar Purkinje neurons. Neuron 7: 81-89.

Llinas R, Sugimori M. 1980. Electrophysiological properties of in vitro Purkinje cell dendrites in mammalian cerebellar slices. J Physiol 305: 197-213.

Llinas R, Yarom Y. 1981a. Electrophysiology of mammalian inferior olivary neurones in vitro. Different types of voltage-dependent ionic conductances. J Physiol 315: 549-567.

Llinas R, Yarom Y. 1981b. Properties and distribution of ionic conductances generating electroresponsiveness of mammalian inferior olivary neurones in vitro. I Physiol 315: 569-584.

Llinas R, Baker R, Sotelo C. 1974. Electrotonic coupling between neurons in cat inferior olive. J Neurophysiol 37: 560-571.

Marek GJ, McMaster SE, Gormezano I, Harvey JA. 1984. The role of the accessory abducens nucleus in the rabbit nictitating membrane response. Brain Res 299: 215-229.

Marr D. 1969. A theory of cerebellar cortex. J Physiol (Lond) 202: 437-470.

Mauk MD. 1997. Roles of cerebellar cortex and nuclei in motor learning: Contradictions or clues? Neuron 18: 343-346.

Mauk MD, Buonomano DV. 2004. The neural basis of temporal processing. Annu Rev Neurosci 27: 307-340.

Mauk MD, Donegan NH. 1997. A model of Pavlovian eyelid conditioning based on the synaptic organization of the cerebellum. Learn Mem 4: $130-158$.

Mauk MD, Steinmetz JE, Thompson RF. 1986. Classical conditioning using stimulation of the inferior olive as the unconditioned stimulus. Proc Natl Acad Sci 83: 5349-5353.

McCormick DA, Thompson RF. 1984. Neuronal responses of the rabbit cerebellum during acquisition and performance of a classically conditioned nictitating membrane-eyelid response. J Neurosci 4: 2811-2822.

McCormick DA, Lavond DG, Clark GA, Kettner RE, Rising CE, Thompson RF. 1981. The engram found? Role of the cerebellum in classical conditioning of nictitating membrane and eyelid responses. B Psychonomic Soc 18: 103-105.

McCormick DA, Clark GA, Lavond DG, Thompson RF. 1982. Initial localization of the memory trace for a basic form of learning. Proc Nat Acad Sci 79: 2731-2735.

McCormick DA, Steinmetz JE, Thompson RF. 1985. Lesions of the inferior olivary complex cause extinction of the classically conditioned eyeblink response. Brain Res 359: 120-130.

Medina JF, Lisberger SG. 2008. Links from complex spikes to local plasticity and motor learning in the cerebellum of awake-behaving monkeys. Nat Neurosci 11: 1185-1192.

Medina JF, Mauk MD. 1999. Simulations of cerebellar motor learning: Computational analysis of plasticity at the mossy fiber to deep nucleus synapse. J Neurosci 19: 7140-7151.

Medina JF, Mauk MD. 2000. Computer simulation of cerebella information processing. Nat Neurosci 3 Suppl: 1205-1211.

Medina JF, Garcia KS, Nores WL, Taylor NM, Mauk MD. 2000. Timing mechanisms in the cerebellum: Testing predictions of a large-scale computer simulation. J Neurosci 20: 5516-5525.

Medina JF, Garcia KS, Mauk MD. 2001. A mechanism for savings in the cerebellum. J Neurosci 21: 4081-4089.

Medina JF, Nores WL, Mauk MD. 2002. Inhibition of climbing fibers is a signal for the extinction of conditioned eyelid responses. Nature 416: 330-333

Mihailoff GA. 1993. Cerebellar nuclear projections from the basilar pontine nuclei and nucleus reticularis tegmenti pontis as demonstrated with PHA-L tracing in the rat. J Comp Neurol 330: 130-146. 
Mihailoff GA, Watt CB. 1981. Cerebral cortical afferent terminations on identified spiny basilar pontine neurons, a combined Golgi-EM degeneration study. Brain Res Bull 6: 227-234.

Mihailoff GA, Lee H, Watt CB, Yates R. 1985. Projections to the basilar pontine nuclei from face sensory and motor regions of the cerebral cortex in the rat. J Comp Neurol 237: 251-263.

Mihailoff GA, Kosinski RJ, Azizi SA, Border BG. 1989. Survey of noncortical afferent projections to the basilar pontine nuclei: A retrograde tracing study in the rat. J Comp Neurol 282: 617-643.

Mintz M, Lavond DG, Zhang AA, Yun Y, Thompson RF. 1994. Unilatera inferior olive NMDA lesion leads to unilateral deficit in acquisition and retention of eyelid classical conditioning. Behav Neural Biol 61: $218-224$.

Mojtahedian S, Kogan DR, Kanzawa SA, Thompson RF, Lavond DG. 2007. Dissociation of conditioned eye and limb responses in the cerebellar interpositus. Physiol Behav 91: 9-14.

Moore JW, Desmond JE, Berthier NE, Blazis DE, Sutton RS, Barto AG. 1986. Simulation of the classically conditioned nictitating membrane response by a neuron-like adaptive element: Response topography, neuronal firing, and interstimulus intervals. Behav Brain Res 21: $143-154$.

Moore JW, Desmond JE, Berthier NE. 1989. Adaptively timed conditioned responses and the cerebellum: A neural network approach. Biol Cybern 62: $17-28$.

Mower G, Gibson A, Robinson F, Stein J, Glickstein M. 1980. Visual pontocerebellar projections in the cat. J Neurophysiol 43: 355-366.

Neufeld M, Mintz M. 2001. Involvement of the amygdala in classical conditioning of eyeblink response in the rat. Brain Res 889: 112-117.

Nicholson DA, Freeman JH Jr. 2002. Neuronal correlates of conditioned inhibition of the eyeblink response in the anterior interpositus nucleus. Behav Neurosci 116: 22-36.

Nicholson DA, Freeman JH Jr. 2003a. Addition of inhibition in the olivocerebellar system and the ontogeny of a motor memory. Nat Neurosci 6: 532-537.

Nicholson DA, Freeman JH Jr. 2003b. Developmental changes in evoked Purkinje cell complex spike responses. J Neurophysiol 90: 2349-2357.

Nolan BC, Freeman JH Jr. 2005. Purkinje cell loss by OX7-saporin impairs excitatory and inhibitory eyeblink conditioning. Behav Neurosci 119: 190-201.

Nolan BC, Freeman JH. 2006. Purkinje cell loss by OX7-saporin impairs acquisition and extinction of eyeblink conditioning. Learn Mem 13: $359-365$.

Norris SA, Hathaway EN, Taylor JA, Thach WT. 2011. Cerebellar inactivation impairs memory of learned prism gaze-reach calibrations. $J$ Neurophysiol 105: 2248-2259.

Nowak AJ, Marshall-Goodell B, Kehoe EJ, Gormezano I. 1997. Elicitation, modification, and conditioning of the rabbit nictitating membrane response by electrical stimulation in the spinal trigeminal nucleus, inferior olive, interpositus nucleus, and red nucleus. Behav Neurosci 111: $1041-1055$.

Oakley DA, Russell IS. 1972. Neocortical lesions and Pavlovian conditioning. Physiol Behav 8: 915-926.

Oakley DA, Russell IS. 1975. Role of cortex in Pavlovian discrimination learning. Physiol Behav 15: 315-321.

Oakley DA, Russell IS. 1976. Subcortical nature of Pavlovian differentiation in the rabbit. Physiol Behav 17: 947-954.

Oakley DA, Russell IS. 1977. Subcortical storage of Pavlovian conditioning in the rabbit. Physiol Behav 18: 931-937.

O'Connor KN, Allison TL, Rosenfield ME, Moore JW. 1997. Neural activity in the medial geniculate nucleus during auditory trace conditioning. Exp Brain Res 113: 534-556.

Ohyama T, Nores WL, Mauk MD. 2003. Stimulus generalization of conditioned eyelid responses produced without cerebellar cortex: Implications for plasticity in the cerebellar nuclei. Learn Mem 10: 346-354.

Ohyama T, Nores WL, Medina JF, Riusech FA, Mauk MD. 2006. Learning-induced plasticity in deep cerebellar nucleus. J Neurosci 26: 12656-12663.

Parker KL, Zbarska S, Carrel AJ, Bracha V. 2009. Blocking GABAA neurotransmission in the interposed nuclei: Effects on conditioned and unconditioned eyeblinks. Brain Res 1292: 25-37.

Pellegrini JJ, Horn AK, Evinger C. 1995. The trigeminally evoked blink reflex. I. Neuronal circuits. Exp Brain Res 107: 166-180.

Perrett SP, Ruiz BP, Mauk MD. 1993. Cerebellar cortex lesions disrupt learning-dependent timing of conditioned eyelid responses. J Neurosci 13: $1708-1718$.

Pugh JR, Raman IM. 2008. Mechanisms of potentiation of mossy fiber EPSCs in the cerebellar nuclei by coincident synaptic excitation and inhibition. J Neurosci 28: 10549-10560.

Pugh JR, Raman IM. 2009. Nothing can be coincidence: Synaptic inhibition and plasticity in the cerebellar nuclei. Trends Neurosci 32: $170-177$.
Raymond JL, Lisberger SG, Mauk MD. 1996. The cerebellum: A neuronal learning machine? Science 272: 1126-1131.

Rosen DJ, Steinmetz JE, Thompson RF. 1989. Classical discrimination conditioning of the rabbit's eyelid response using pontine stimulation as a conditioned stimulus. Behav Neural Biol 52: 51-62.

Rosenfield ME, Moore JW. 1983. Red nucleus lesions disrupt the classically conditioned nictitating membrane response in rabbits. Behav Brain Res 10: $393-398$.

Rosenfield ME, Moore JW. 1985. Red nucleus lesions impair acquisition of the classically conditioned nictitating membrane response but not eye-to-eye savings or unconditioned response amplitude. Behav Brain Res 17: 77-81.

Rosenfield ME, Dovydaitis A, Moore JW. 1985. Brachium conjuntivum and rubrobulbar tract: Brain stem projections of red nucleus essential for the conditioned nictitating membrane response. Physiol Behav 34: $751-759$.

Ruigrok TJ, Hensbroek RA, Simpson JI. 2011. Spontaneous activity signatures of morphologically identified interneurons in the vestibulocerebellum. J Neurosci 31: 712-724.

Schade Powers A, Coburn-Litvak P, Evinger C. 2010. Conditioned eyelid movement is not a blink. J Neurophysiol 103: 641-647.

Schneiderman N, Fuentes I, Gormezano I. 1962. Acquisition and extinction of the classically conditioned eyelid response in the albino rabbit. Science 136: 650-652.

Sears LL, Steinmetz JE. 1991. Dorsal accessory inferior olive activity diminishes during acquisition of the rabbit classically conditioned eyelid response. Brain Res 545: 114-122.

Shibuki K, Gomi H, Chen L, Bao S, Kim JJ, Wakatsuki H, Fujisaki T, Fujimoto K, Katoh A, Ikeda T, et al. 1996. Deficient cerebellar long-term depression, impaired eyeblink conditioning, and normal motor coordination in GFAP mutant mice. Neuron 16: 587-599.

Shinoda Y, Sugiuchi Y, Futami T, Izawa R. 1992. Axon collaterals of mossy fibers from the pontine nucleus in the cerebellar dentate nucleus. $J$ Neurophysiol 67: 547-560.

Shinoda Y, Sugihara I, Wu HS, Sugiuchi Y. 2000. The entire trajectory of single climbing and mossy fibers in the cerebellar nuclei and cortex. Prog Brain Res 124: $173-186$.

Solomon PR, Lewis JL, Loturco JJ, Steinmetz JE, Thompson RF. 1986. The role of the middle cerebellar peduncle in acquisition and retention of the rabbits classically conditioned nictitating-membrane response. $B$ Psychonomic Soc 24: 75-78.

Steinmetz JE. 1990. Classical nictitating membrane conditioning in rabbits with varying interstimulus intervals and direct activation of cerebellar mossy fibers as the CS. Behav Brain Res 38: 97-108.

Steinmetz JE, Rosen DJ, Chapman PF, Lavond DG, Thompson RF. 1986. Classical conditioning of the rabbit eyelid response with a mossy-fiber stimulation CS: I. Pontine nuclei and middle cerebellar peduncle stimulation. Behav Neurosci 100: 878-887.

Steinmetz JE, Logan CG, Rosen DJ, Thompson JK, Lavond DG, Thompson RF. 1987. Initial localization of the acoustic conditioned stimulus projection system to the cerebellum essential for classical eyelid conditioning. Proc Natl Acad Sci 84: 3531-3535.

Steinmetz JE, Lavond DG, Thompson RF. 1989. Classical conditioning in rabbits using pontine nucleus stimulation as a conditioned stimulus and inferior olive stimulation as an unconditioned stimulus. Synapse 3: $225-233$.

Steinmetz JE, Lavond DG, Ivkovich D, Logan CG, Thompson RF. 1992a. Disruption of classical eyelid conditioning after cerebellar lesions: Damage to a memory trace system or a simple performance deficit? J Neurosci 12: 4403-4426.

Steinmetz JE, Logue SF, Steinmetz SS. 1992b. Rabbit classically conditioned eyelid responses do not reappear after interpositus nucleus lesion and extensive post-lesion training. Behav Brain Res 51: 103-114.

Sugihara I, Wu H, Shinoda Y. 1999. Morphology of single olivocerebellar axons labeled with biotinylated dextran amine in the rat. J Comp Neurol 414: $131-148$.

Sugihara I, Wu HS, Shinoda Y. 2001. The entire trajectories of single olivocerebellar axons in the cerebellar cortex and their contribution to cerebellar compartmentalization. J Neurosci 21: 7715-7723.

Svensson P, Bengtsson F, Hesslow G. 2006. Cerebellar inhibition of inferior olivary transmission in the decerebrate ferret. Exp Brain Res 168: $241-253$.

Taub AH, Mintz M. 2010. Amygdala conditioning modulates sensory input to the cerebellum. Neurobiol Learn Mem 94: 521-529.

Tracy JA, Thompson JK, Krupa DJ, Thompson RF. 1998. Evidence of plasticity in the pontocerebellar conditioned stimulus pathway during classical conditioning of the eyeblink response in the rabbit. Behav Neurosci 112: 267-285.

Trigo JA, Gruart A, Delgado-Garcia JM. 1999. Discharge profiles of abducens, accessory abducens, and orbicularis oculi motoneurons during reflex and conditioned blinks in alert cats. J Neurophysiol 81: $1666-1684$. 
Vogel RW, Amundson JC, Lindquist DH, Steinmetz JE. 2009. Eyeblink conditioning during an interstimulus interval switch in rabbits (Oryctolagus cuniculus) using picrotoxin to disrupt cerebellar cortical input to the interpositus nucleus. Behav Neurosci 123: 62-74.

Voneida TJ. 2000. The effect of brachium conjunctivum transection on a conditioned limb response in the cat. Behav Brain Res 109: $167-175$.

Voneida TJ, Christie D, Bogdanski R, Chopko B. 1990. Changes in instrumentally and classically conditioned limb-flexion responses following inferior olivary lesions and olivocerebellar tractotomy in the cat. J Neurosci 10: 3583-3593.

Weber JT, Harting JK. 1980. The efferent projections of the pretectal complex: An autoradiographic and horseradish peroxidase analysis. Brain Res 194: 1-28.

Weeks AC, Connor S, Hinchcliff R, LeBoutillier JC, Thompson RF, Petit TL. 2007. Eyeblink conditioning is associated with changes in synaptic ultrastructure in the rabbit interpositus nuclei. Learn Mem 14: 385-389.

Weiss C, Disterhoft JF. 1985. Connections of the rabbit abducens nucleus. Brain Res 326: $172-178$.

Wells GR, Hardiman MJ, Yeo CH. 1989. Visual projections to the pontine nuclei in the rabbit: Orthograde and retrograde tracing studies with WGA-HRP. J Comp Neurol 279: 629-652.

Welsh JP, Harvey JA. 1989. Cerebellar lesions and the nictitating membrane reflex: Performance deficits of the conditioned and unconditioned response. J Neurosci 9: 299-311.
Welsh JP, Harvey JA. 1991. Pavlovian conditioning in the rabbit during inactivation of the interpositus nucleus. J Physiol 444: 459-480.

Welsh JP, Harvey JA. 1998. Acute inactivation of the inferior olive blocks associative learning. Eur J Neurosci 10: 3321-3332.

Woodruff-Pak DS, Lavond DG, Logan CG, Steinmetz JE, Thompson RF. 1993. Cerebellar cortical lesions and reacquisition in classical conditioning of the nictitating membrane response in rabbits. Brain Res 608: $67-77$.

Yeo CH, Hardiman MJ. 1992. Cerebellar cortex and eyeblink conditioning: A reexamination. Exp Brain Res 88: 623-638.

Yeo CH, Hardiman MJ, Glickstein M. 1985a. Classical conditioning of the nictitating membrane response of the rabbit. I. Lesions of the cerebellar nuclei. Exp Brain Res 60: 87-98.

Yeo CH, Hardiman MJ, Glickstein M. 1985b. Classical conditioning of the nictitating membrane response of the rabbit. II. Lesions of the cerebellar cortex. Exp Brain Res 60: 99-113.

Yeo CH, Hardiman MJ, Glickstein M. 1986. Classical conditioning of the nictitating membrane response of the rabbit. IV. Lesions of the inferior olive. Exp Brain Res 63: 81-92.

Zbarska S, Holland EA, Bloedel JR, Bracha V. 2007. Inferior olivary inactivation abolishes conditioned eyeblinks: Extinction or cerebellar malfunction? Behav Brain Res 178: 128-138.

Received May 17, 2011; accepted in revised form August 17, 2011. 


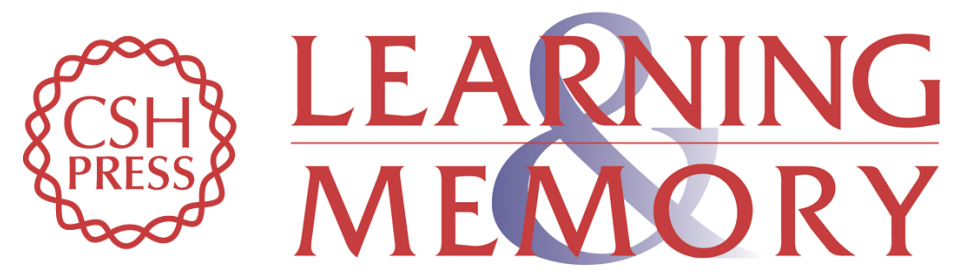

\section{Neural circuitry and plasticity mechanisms underlying delay eyeblink conditioning}

John H. Freeman and Adam B. Steinmetz

Learn. Mem. 2011, 18:

Access the most recent version at doi:10.1101//m.2023011

References This article cites 201 articles, 60 of which can be accessed free at: http://learnmem.cshlp.org/content/18/10/666.full.html\#ref-list-1

License

Email Alerting Receive free email alerts when new articles cite this article - sign up in the box at the Service top right corner of the article or click here. 